\title{
Scalable nanostructuring on polymer by a SiC stamp: Optical and wetting effects
}

\author{
Argyraki, Aikaterini; Lu, Weifang; Petersen, Paul Michael; Ou, Haiyan
}

Published in:

Proceedings of SPIE

Link to article, DOI:

$10.1117 / 12.2186317$

Publication date:

2015

Document Version

Publisher's PDF, also known as Version of record

Link back to DTU Orbit

Citation (APA):

Argyraki, A., Lu, W., Petersen, P. M., \& Ou, H. (2015). Scalable nanostructuring on polymer by a SiC stamp: Optical and wetting effects. In E. M. Campo, E. A. Dobisz, \& L. A. Eldada (Eds.), Proceedings of SPIE (Vol. 9556). [955607] SPIE - International Society for Optical Engineering. Proceedings of SPIE - The International Society for Optical Engineering https://doi.org/10.1117/12.2186317

\section{General rights}

Copyright and moral rights for the publications made accessible in the public portal are retained by the authors and/or other copyright owners and it is a condition of accessing publications that users recognise and abide by the legal requirements associated with these rights.

- Users may download and print one copy of any publication from the public portal for the purpose of private study or research.

- You may not further distribute the material or use it for any profit-making activity or commercial gain

- You may freely distribute the URL identifying the publication in the public portal 


\title{
Scalable nanostructuring on polymer by a SiC stamp: optical and wetting effects
}

\author{
Aikaterini Argyraki*a, Weifang Lu ${ }^{b}$, Paul Michael Petersen ${ }^{a}$, Haiyan $\mathrm{Ou}^{\mathrm{b}}$ \\ ${ }^{\mathrm{a}}$ Department of Photonics Engineering, Technical University of Denmark, Frederiksborgvej 399, \\ DK-4000, Roskilde, Denmark \\ ${ }^{\mathrm{b}}$ Department of Photonics Engineering, Technical University of Denmark, DK-2800, Kgs. Lyngby, \\ Denmark
}

\begin{abstract}
A method for fabricating scalable antireflective nanostructures on polymer surfaces (polycarbonate) is demonstrated. The transition from small scale fabrication of nanostructures to a scalable replication technique can be quite challenging. In this work, an area per print corresponding to a 2-inch-wafer, is presented. The initial nanopatterning is performed on $\mathrm{SiC}$ in a 2-step process. Depending on the nanostructures the transmission of the $\mathrm{SiC}$ surface can be increased or suppressed (average height of nanostructures $\sim 300 \mathrm{~nm}$ and $\sim 600 \mathrm{~nm}$, respectively) while the reflectance is decreased, when compared to a bare surface. The reflectance of $\mathrm{SiC}$ can be reduced down to $0.5 \%$ when the $\sim 600 \mathrm{~nm}$ nanostructures are applied on the surface (bare surface reflectance 25\%). The texture of the green $\mathrm{SiC}$ color is changed when the different nanostructures are apparent.

The $\sim 600 \mathrm{~nm} \mathrm{SiC} \mathrm{nanostructures} \mathrm{are} \mathrm{replicated} \mathrm{on} \mathrm{polymer} \mathrm{through} \mathrm{a} \mathrm{process} \mathrm{flow} \mathrm{that} \mathrm{involved} \mathrm{hot} \mathrm{embossing} \mathrm{and}$ galvanization. The resulted polymer structures have similar average height and exhibit more rounded edges than the initial $\mathrm{SiC}$ nanostructures. The polymer surface becomes antireflective and hydrophobic after nanostructuring. The contact angle changes from 68 (bare) to 123 (nanostructured) degrees. The optical effect on the polymer surface can be maximized by applying a thin aluminum (Al) layer coating on the nanostructures (bare polymer reflectance $11 \%$, nanostructured polymer reflectance 5\%, Al coated nanostructured polymer reflectance $3 \%$ ).
\end{abstract}

The optical measurements were performed with an integrating sphere and a spectrometer. The contact angles were measured with a drop shape analyzer. The nanostructures were characterized with scanning electron microscopy.

Keywords: Scalable polymer nanostructuring, Optical effects, Wetting effects, hot embossing, galvanization, SiC

\section{INTRODUCTION}

Nanoengineering enables a controllable fabrication of interfaces at the micro/nanoscopic level; pushing performance of innumerable devices towards their optimum limits. The applications can be ranging from implants (dental, ${ }^{1,2}$ orthopedic ${ }^{3}$ ) to catalysis, ${ }^{4}$ photovoltaics,${ }^{5,6}$ light emitting diodes, ${ }^{7,8}$ biosensors, ${ }^{9}$ and drug delivery. ${ }^{10}$ The unbreakable relationship between nanotopography and mechanical, physical and chemical properties of materials permits the usage of functional micro-nanostructuring. Though, in order for the technology to be adopted the fabrication process should be rapid, lowcost and applicable on wafer-scale high throughput. Nano-pattern definition can be achieved by various techniques like, electron-beam lithography, ${ }^{11}$ block copolymer micelle nanolithography, ${ }^{12}$ nanosphere lithography ${ }^{13}$ and self-assembly of noble metals ${ }^{14}$ etc. However, such techniques can rarely accomplish all aforementioned requirements. Moreover, polymer materials are gaining interest both as semiconductors ${ }^{15}$ and conductors ${ }^{16,17}$ due to their low cost and flexibility; offering exiting alternatives to traditional materials.

In this work we report a 2-step method to fabricate nanostructures on wafer scale on $\mathrm{SiC}$ and their replication on a polymer surface. The resulted polymer structures have similar average height and exhibit more rounded edges than the initial nanostructures. The polymer surface becomes antireflective and hydrophobic after nanostructuring, demonstrating how nanotopography can change physical properties of a surface, namely optical and wetting properties.

Nanoengineering: Fabrication, Properties, Optics, and Devices XII, edited by

Eva M. Campo, Elizabeth A. Dobisz, Louay A. Eldada, Proc. of SPIE Vol. 9556

$955607 \cdot$ (c) 2015 SPIE · CCC code: 0277-786X/15/\$18 - doi: 10.1117/12.2186317 


\section{WAFER-SCALE NANOSTRUCTURING OF SIC STAMP}

The fabrication flow for nanopatterning on $\mathrm{SiC}$ and optimization details from $1 \times 1 \mathrm{~cm}^{2}$ areas could be found in. ${ }^{18}$ The processing parameters have been slightly modified in order to fit wafer-scale production (2-inch wafers). A thin Al layer $(40 \mathrm{~nm})$ was deposited on the 2-inch $\mathrm{SiC}$ surface. Reactive ion etching (RIE) was performed for 30 minutes with a mixture of $\mathrm{CF}_{4}$ and $\mathrm{O}_{2}$ gases (24 sccm and $6 \mathrm{sccm}$ respectively) at 130 Watt RF power and $100 \mathrm{mT}$ chamber pressure. The processed 2-inch $\mathrm{SiC}$ wafers demonstrate extreme reflection suppression compared to unprocessed wafers (as shown in Fig. 1)



Figure 1. Two 2-inch SiC wafers with (a) and without (b) nanostructures. The nanostructured wafer demonstrates extreme reflection suppression.

Depending on the processing parameters the nanostructure morphology can be changed from low to high nanostructures, average height of nanostructures $\sim 300 \mathrm{~nm}$ and $\sim 600 \mathrm{~nm}$, respectively (Fig. 2). The nanostructure morphology was characterized with scanning electron microscope (SEM, Zeiss Supra VP 40). The morphology of nanostructures affects the color texture and transmission properties of $\mathrm{SiC}$ samples; the transmission of the $\mathrm{SiC}$ surface can be increased or suppressed (Fig. 3), when compared to a bare surface.
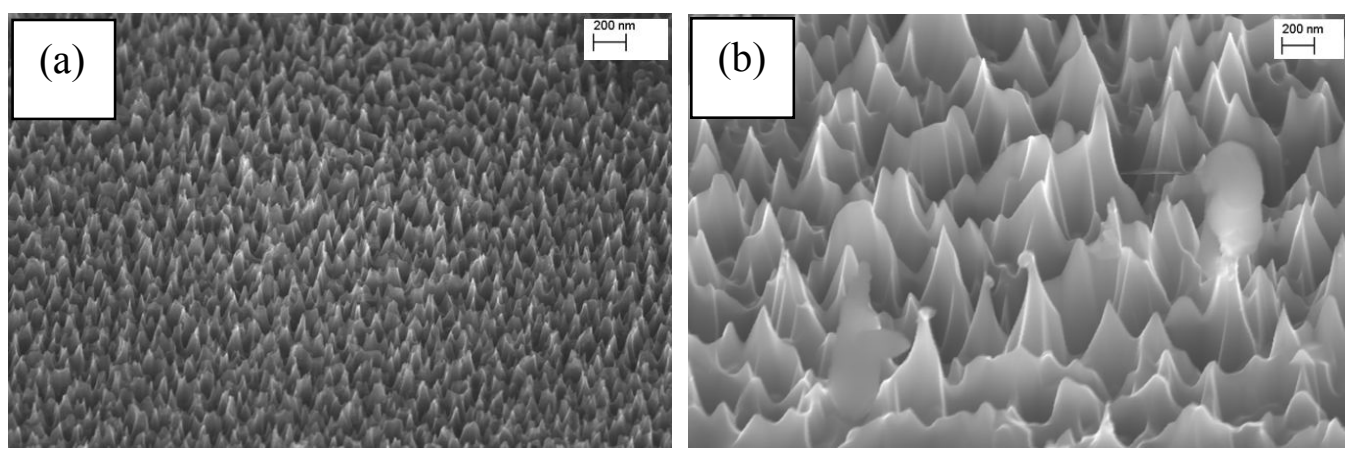

Figure 2. Oblique-view scanning electron microscope (SEM) images of a SiC samples with low nanostructures $~ 300 \mathrm{~nm}$ (a) and high nanostructures $\sim 600 \mathrm{~nm}$ (b).

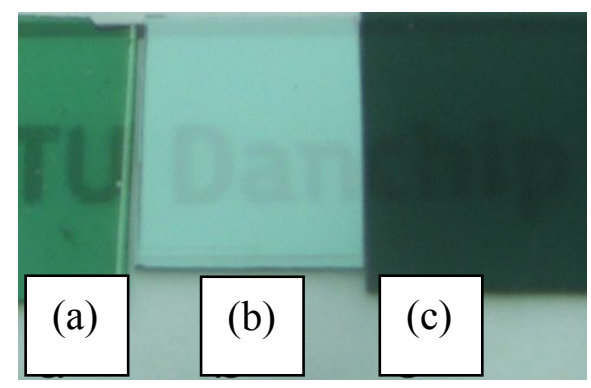

Figure 3. Photos of bare and nanostructured $\mathrm{SiC}$. a) $\mathrm{SiC}$ with low nanostructures on the surface. b) Bare $\mathrm{SiC}$. c) $\mathrm{SiC}$ with high nanostructures. Color texture and transmission properties of $\mathrm{SiC}$ samples (smaller than $1 \times 1 \mathrm{~cm}^{2}$ ) depend on the nanostructures applied. The clarity of the text under the samples is maximum for sample a. 
Optical measurements were performed with an integrating sphere (8/8deg incident angle) and a spectrometer (QE 65000, Ocean Optics) to confirm the results of the altered optical properties due to nanostructuring; a halogen lamp was used as light source. Reflection and transmission spectra are presented in Fig. 4. The average reflectance (integration over visible wavelengths) was suppressed from $25 \%$ (bare surface) to $5 \%$ and $0.5 \%$ respectively when low nanostructures and high nanostructures were applied. The average transmittance was increased from $33 \%$ (bare surface) to $37 \%$ after low nanostructures were applied. To the contrary, when high nanostructures were applied the average transmittance was reduced to $13 \%$. The wetting properties of the $\mathrm{SiC}$ surface are changed after nanostructuring from hydrophilic to hydrophobic ${ }^{18}$.
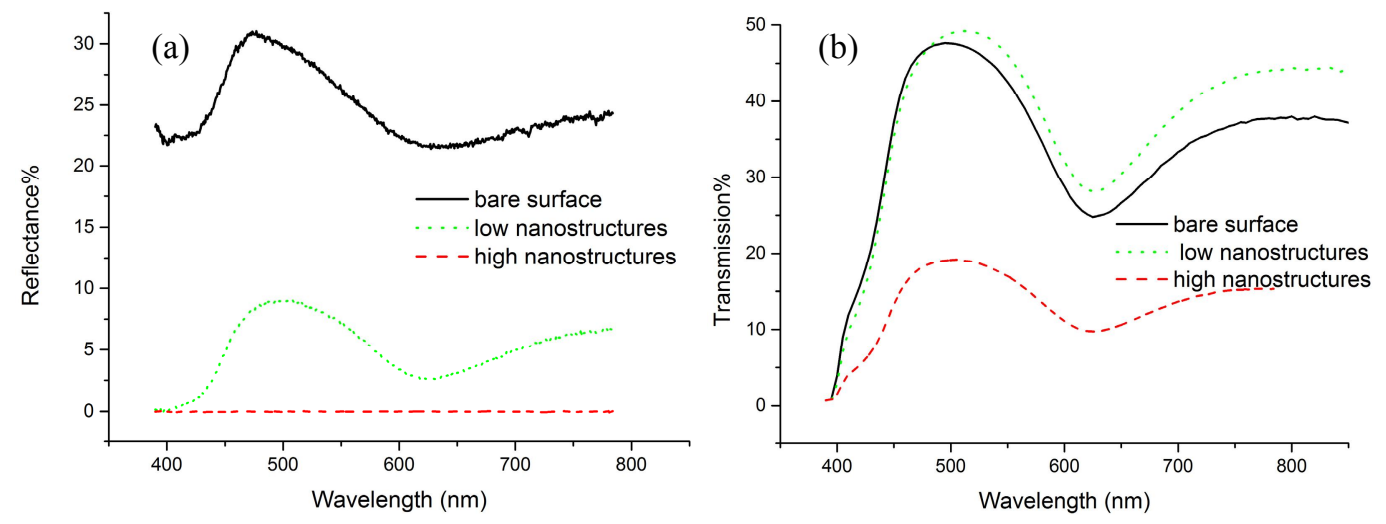

Figure 4. (a): Reflectance spectra from bare and nanostructured SiC surfaces. The reflection of nanostructured samples is suppressed compared to the bare surface. (b): Transmission spectra from bare and nanostructured SiC surfaces. Transmission can be increased or suppressed, depending on the type of nanostructures applied.

\section{REPLICATION OF NANOSTRUCTURES ON A POLYMER SURFACE}

The nanostructures that resulted in the most effective antireflective surface $(\sim 600 \mathrm{~nm})$ were replicated on polymer through a process flow that involved hot embossing and galvanization (Fig. 5). The resulted polymer structures have similar average height and exhibit more rounded edges than the initial $\mathrm{SiC}$ nanostructures (Fig. 6 right). When a thin aluminum (Al) layer $(\sim 40 \mathrm{~nm})$ was deposited on the nanostructured surface, the $\mathrm{Al}$ film followed the morphology of the underlying surface (Fig. 6 left).

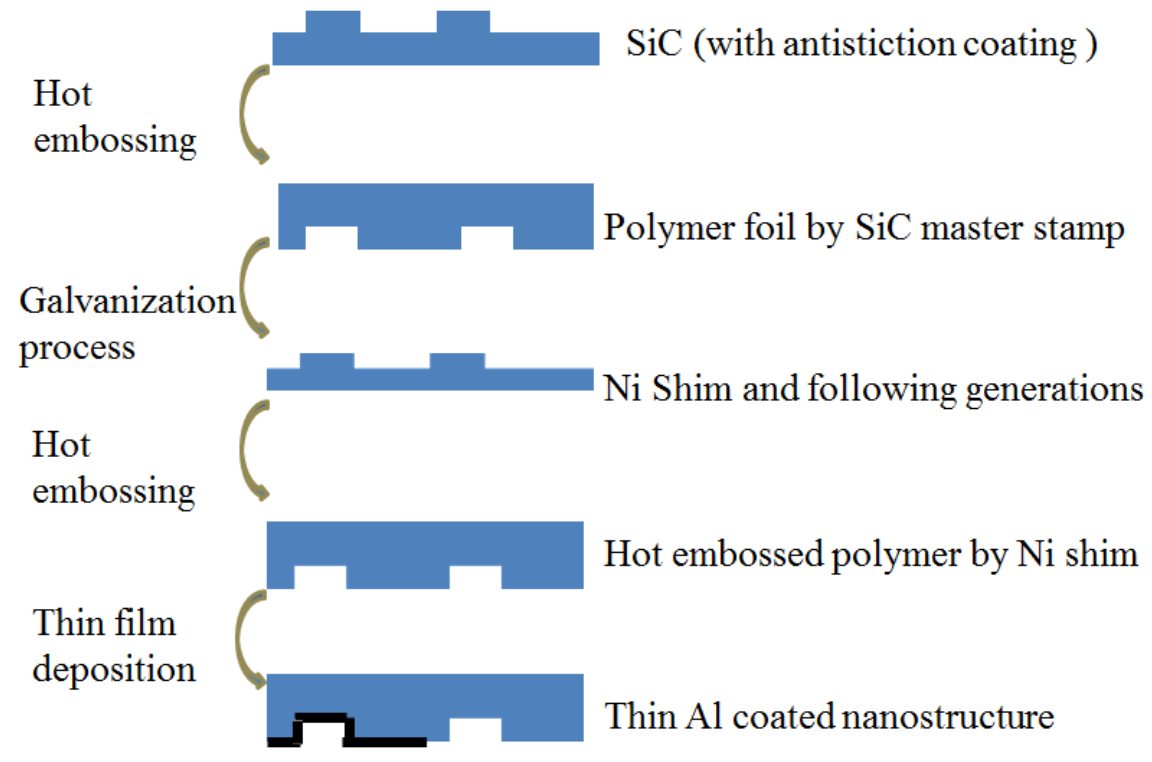

Figure 5. Schematic illustration of the polymer nanostructured surface process flow. 

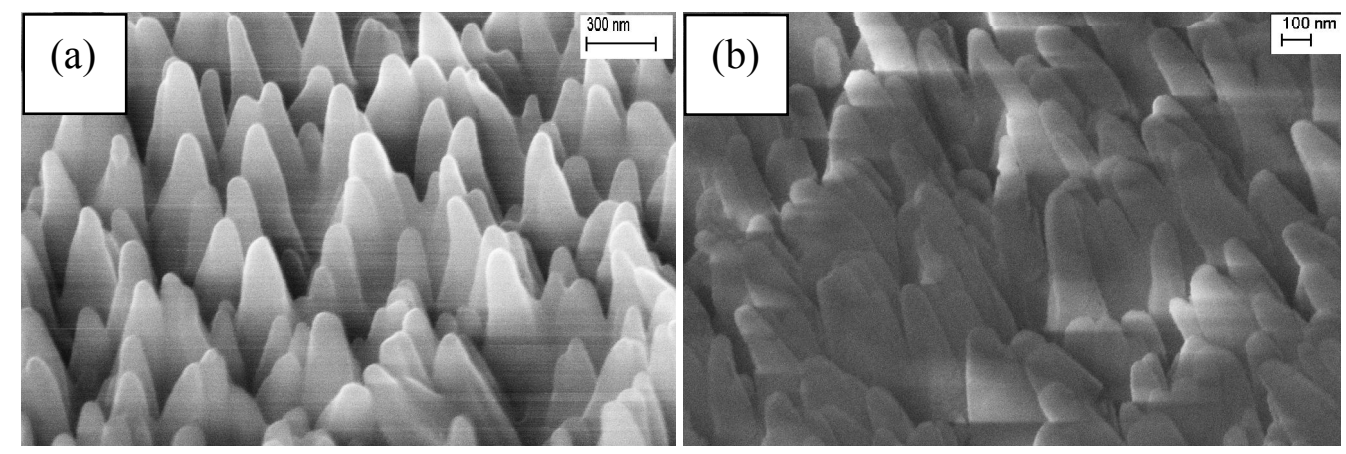

Figure 6. (a): SEM image of nanostructured polymer surface. (b): SEM image of Al coated nanostructured polymer surface $(\sim 40 \mathrm{~nm})$. The Al layer follows the morphology of the underlying surface. The replicated nanostructures exhibit more rounded edges.

The color texture of the polymer surface changes significantly when nanostructures are applied (Fig. 7 ); from mirror like (Al coated bare surface, Fig. 7a) to grey-black (Al coated nanostructured surface, Fig. 7b), and foggy-white (nanostructured surface, Fig. 7c) to transparent see-through (bare surface, Fig. 7d ). The transparency of the polymer surface is also affected as illustrated in Fig. 7 (right).
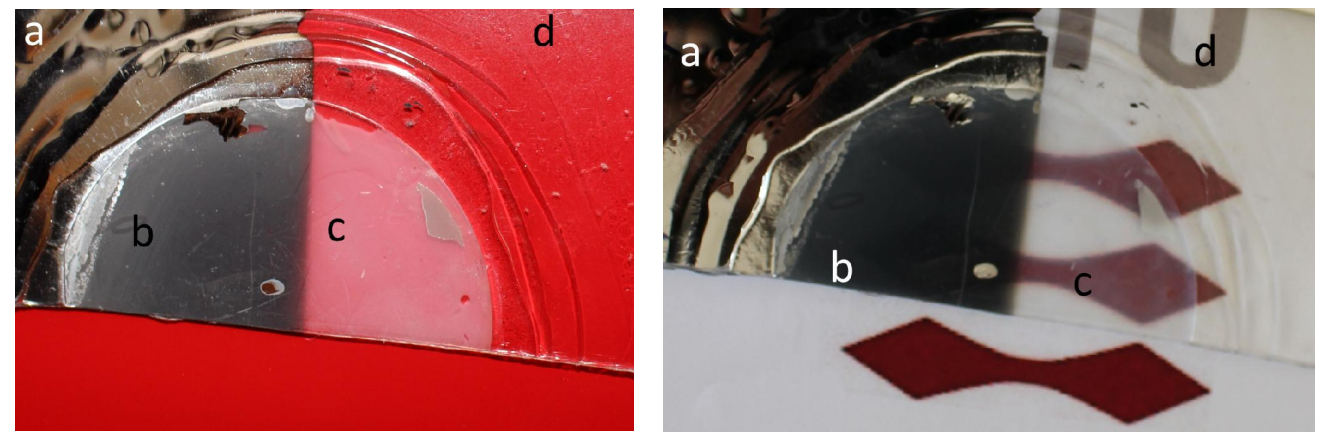

Figure 7 Photos of Al coated (a), nanostructured and Al coated (b) nanostructured (c) and bare (d) polymer surface. Left: The color texture of the polymer surface changes significantly after nanostructuring (foggy-white, c); and nanostructuring and thin film coating (black, b). Right: The transparency of the polymer surface is affected by the presence of the nanostructures and the Al coating. At the border between the Al coated (b) and not Al coated region (c) one can observe that transparency gradually increases, probably due to that the Al thickness gradual decrease.

The optical properties of the nanostructured polymer surface and nanostructured and Al coated polymer surface were measured as described in section 2. Their reflection and transmission spectra are presented respectively in Fig. 8 (a) and (b). The average reflectance of the polymer surface was reduced from $11 \%$ (bare) to $5 \%$ when the nanostructures were applied. A further reduction to $3 \%$ was achieved after the thin Al layer was deposited on the surface. The average transmittance of the polymer surface was changed from $88 \%$ (bare) to $85 \%$ when nanostructures were applied and drastically reduced to $33 \%$ after the $\mathrm{Al}$ coating. Moreover, the wetting properties of the various surfaces namely bare surface, nanostructured surface, Al coated bare and Al coated nanostructured surface were measured with a drop shape analyzer (Krüss DSA 100S). The surfaces were transformed from hydrophilic (68/75 degrees water contact angle) to hydrophobic (123/132 degrees water contact angle) after the nanostructures were applied (respectively for polymer and Al coated). The water contact angle measurements are shown in Fig. 9.

\section{CONCLUSIONS}

We have demonstrated scalable ( 2 inch area) nanostructuring on a polymer surface by a SiC stamp and studied the optical and wetting properties of the related surfaces before and after nanostructuring. It was shown that the color texture of the surfaces ( $\mathrm{SiC}$ and polymer surface) is affected significantly by the presence of nanostructures. Moreover, it was demonstrated that when a thin Al coating is applied on the nanostructured polymer surface the reflectance and 
transmittance can be even further reduced. Finally, we have shown that the presence of the fabricated nanostructures on a surface can transform it from hydrophilic to hydrophobic.
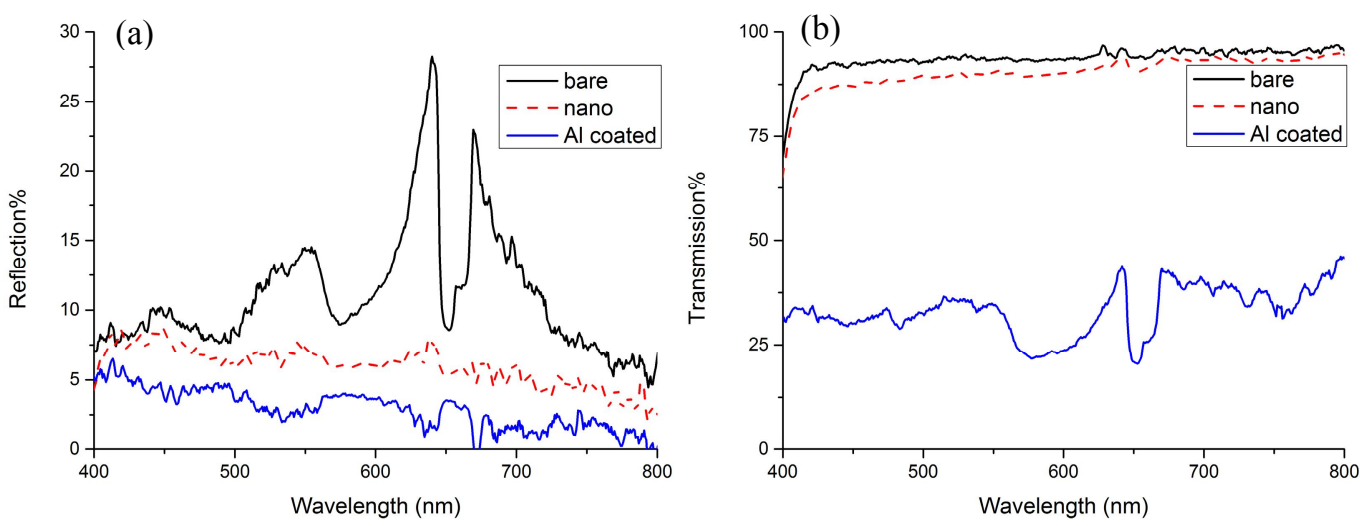

Figure 8. (a): Reflectance spectra from bare, nanostructured and nanostructured and Al coated polymer surfaces. The reflection of nanostructured and Al coated samples is suppressed compared to the nanostructured and bare surface. (b): Transmission spectra from bare and nanostructured and nanostructured and Al coated polymer surfaces. Transmission is drastically decreased when a thin Al coating is applied on the nanostructured surface.
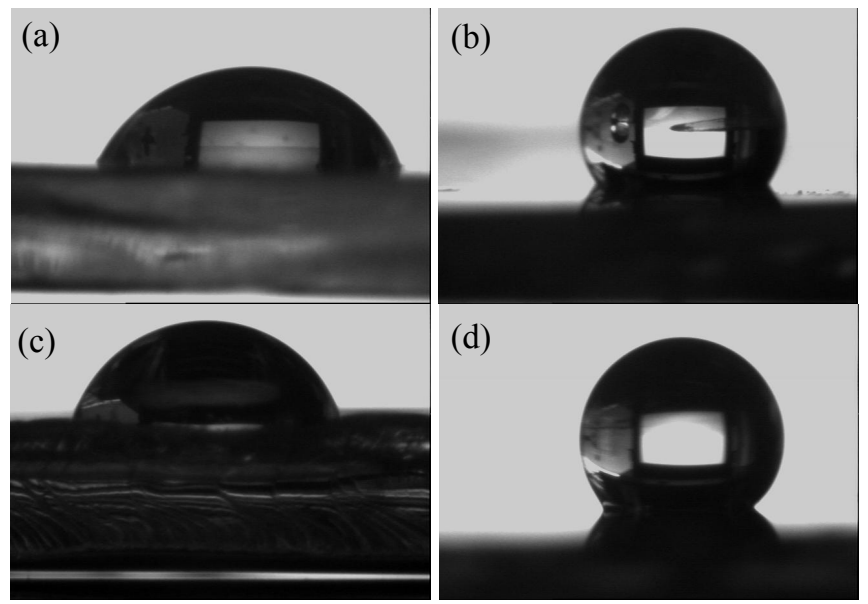

Figure 9. (a)Water contact angles of polymer surface without and (b) with nanostructures. (c)Water contact angles of Al coated surface without and (d) with nanostructures. The nanostructures modify the surfaces from hydrophilic to hydrophobic.

\section{REFERENCES}

[1] Lavenus, S., Louarn, G. and Layrolle, P., "Nanotechnology and dental implants," International Journal of Biomaterials 2010, Article ID 915327, 9 pages (2010).

[2] Naik, S., Galagali, G., Nidawani, P., Behera, S. S., Sufiyan, M. K. and Kohli, R., "NANO SURFACE COATINGS \& DENTAL IMPLANTS-A REVIEW," Surface and dental implants 2 (5), 66-70 (2014).

[3] Streicher, R. M., Schmidt, M. and Fiorito, S., "Nanosurfaces and nanostructures for artificial orthopedic implants," Nanomedicine 2(6), 861-74 (2007).

[4] Guo, L., Jing, D., Liu, M., Chen, Y., Shen, S., Shi, J. and Zhang, K., "Functionalized nanostructures for enhanced photocatalytic performance under solar light," Beilstein journal of nanotechnology 5(1), 994-1004 (2014).

[5] Kim, M. S., Kim, J. S., Cho, J. C., Shtein, M., Kim, J. and Guo, L. J., "Flexible conjugated polymer photovoltaic cells with controlled heterojunctions fabricated using nanoimprint lithography," Applied Physics Letters 90(12), 123113 (2007). 
[6] Aryal, M., Buyukserin, F., Mielczarek, K., Zhao, X. M., Gao, J., Zakhidov, A. and Hu, W. W., "Imprinted large-scale high density polymer nanopillars for organic solar cells," Journal of Vacuum Science \& Technology B 26 (6), 2562-2566 (2008).

[7] Boroumand, F. A., Fry, P. W. and Lidzey, D. G., "Nanoscale conjugated-polymer light-emitting diodes," Nano letters 5(1), 67-71 (2005).

[8] Ou, H., Ou, Y., Argyraki, A., Schimmel, S., Kaiser, M., Wellmann, P., Linnarsson, M.K., Jokubavicius, V., Sun, J., Liljedahl, R. and Syväjärvi, M., "Advances in wide bandgap SiC for optoelectronics," The European Physical Journal B 87(3), 1-16 (2014).

[9] Soleymani, L., Fang, Z., Sargent, E. H. and Kelley, S. O., "Programming the detection limits of biosensors through controlled nanostructuring," Nature Nanotechnology 4(12), 844-848 (2009).

[10] Goldberg, M., Langer, R. and Jia, X., "Nanostructured materials for applications in drug delivery and tissue engineering," Journal of Biomaterials Science Polymer Edition 18(3), 241-268 (2007).

[11] Ou, Y., Jokubavicius, V., Hens, P., Kaiser, M., Wellmann, P., Yakimova, R., Syväjärvi, M. and Ou, H., "Broadband and omnidirectional light harvesting enhancement of fluorescent SiC," Opt. Express 20(7), 75757579 (2012).

[12] Brunner, R., Keil, B., Morhard, C., Lehr, D., Draheim, J., Wallrabe, U. and Spatz, J. "Antireflective moth-eye structures on tunable optical silicone membranes," Applied optics 51(19), 4370-4376 (2012).

[13] Ou, Y., Zhu, X., Jokubavicius, V., Yakimova, R., Mortensen, N. A., Syväjärvi, M., Xiao, S. and Ou, H. "Broadband Antireflection and Light Extraction Enhancement in Fluorescent SiC with Nanodome Structures," Sci. Rep. 4, 4662 (2014).

[14] Ou, Y., Aijaz, I., Jokubavicius, V., Yakimova, R., Syväjärvi, M. and Ou, H., "Broadband antireflection silicon carbide surface by self-assembled nanopatterned reactive-ion etching, " Opt. Mater. Express 3(1), 86-94 (2013).

[15] Krebs, F. C., Gevorgyan, S. A., and Alstrup, J., "A roll-to-roll process to flexible polymer solar cells: model studies, manufacture and operational stability studies," Journal of Materials Chemistry 19(30), 5442-5451 (2009).

[16] Argyraki, A., Larsen, S. T., Tanzi, S., \& Taboryski, R. J., "Integration of Polymer Micro-Electrodes for BioSensing," Poster session presented at The Pittsburgh Conference on Analytical Chemistry and Applied Spectroscopy Inc., Orlando, FL, United States (2012).

[17] Larsen, S. T., Argyraki, A., Amato, L., Tanzi, S., Keller, S. S., Rozlosnik, N., and Taboryski, R. J., "Pyrolyzed Photoresist Electrodes for Integration in Microfluidic Chips for Transmitter Detection from Biological Cells, "E C S Electrochemistry Letters 2(5), B5-B7 (2013).

[18] Argyraki, A., Ou, Y., \& Ou, H., "Broadband antireflective silicon carbide surface produced by cost-effective method," Optical Materials Express 3(8), 1119-1126 (2013). 